\title{
Testes e Provas Psicológicas em Portugal
}

SIMÕES, M. R; GONÇALVES, M. M. e ALMEIDA, L. S (Eds.) (1999). Testes e Provas Psicológicas em Portugal (vol. II). Braga: APPORT/SHO.

A prática da Avaliação Psicológica que constitui, reconhecidamente, uma tarefa básica profissional da Psicologia, tem sido discutida e estudada em vários países.

A presente obra tem como editores os pesquisadores Leandro S. Almeida, Mário R. Simões e Miguel M. Gonçalves e consiste no segundo volume da publicação anterior "Provas Psicológicas em Portugal". O livro em questão, reúne um conjunto de trabalhos apresentados na II Mostra de Provas Psicológicas em Portugal, iniciativa integrada à IV Conferência Internacional sobre Avaliação Psicológica: formas e contextos. Faz parte de um projeto que visa divulgar instrumentos e autores de estudos de adaptação e/ou aferição de provas psicológicas para a população portuguesa. A obra é composta por 17 capítulos que estão dispostos em 198 páginas, referentes ao estudo de testes, inventários, escalas e questionários desenvolvidos nas diferentes áreas da Psicologia e sob a autoria de vários estudiosos.

O Primeiro Capítulo é escrito pelos editores desta obra, no qual é feita uma breve apresentação do livro e de um roteiro das questões consideradas mais importantes na utilização de instrumentos de avaliação psicológica.

Miranda, da Faculdade de Psicologia e Ciência da Educação - Universidade de Lisboa, apresenta a Escala Coletiva de Nível Intelectual (ECNI), que é uma bateria para medida da aptidão geral, de aplicação coletiva e de tipo papel e lápis. É feito pela autora um histórico do instrumento, constando natureza e características; estudos portugueses de aferição (amostra de estandardização, procedimento experimental, dados metrológicos e material), estudo da precisão, método teste/reteste, estudo longitudinal, estudos sobre a ECNI - V e avaliação clínica.

No Terceiro Capítulo, Albuquerque e outros (Universidade de Coimbra) discutem o Inventário de Comportamento da Criança para Pais (ICCP), que segundo os autores é um dos instrumentos de avaliação mais conhecidos e utilizados no domínio da psicopatologia infantil e juvenil. Tem como objetivo descrever e avaliar as competências sociais e os problemas de comportamento de crianças e adolescentes (4 a 18 anos de idade). São tratados pelos autores: as indicações, população alvo, aspectos históricos do instrumento, fundamentação teórica, estudos realizados em Portugal - objetivos e metodologia, dados normativos, validade concorrente, validade de constructo, validade relativa a um critério externo, teste/reteste, consistência interna, aplicação e correção, parâmetros possíveis de interpretação dos resultados e avaliação crítica.

O Inventário da Vinculação na Adolescência (IPPA) é discutido por Neves, Soares e Silva. A princípio, são apresentados; indicações, dimensões avaliadas, população alvo, aspecto históricos do instrumento, fundamentação teórica, caracterização dos estudos realizados em Portugal, dados psicométricos, validade, parâmetros possíveis de interpretação dos resultados e avaliação crítica.

Duarte, da Universidade de Lisboa, fala sobre o Inventário das Preocupações de Carreira (IPC), que avalia a previsibilidade de pensar no futuro, ou seja, aquilo que diz respeito ao trabalho do indivíduo e à vida de trabalho. $\mathrm{O}$ autor apresenta o inventário segundo a sua estrutura, fundamentação teórica, população alvo, estudos portugueses, amostra utilizada nesses estudos, dados metrológicos (análise de itens, precisão, validade), material, interpretação de resultados e 
avaliação crítica.

Pinto, da Universidade de Lisboa, no Sexto Capítulo, apresenta a Bateria de Testes e Aptidões (GA TB). É um instrumento multifatorial, utilizado na seleção e na orientação escolar e profissional. A autora descreve de modo claro e simples a Bateria, destacando: população alvo; composição e dimensões avaliadas; história e fundamentação teórica; caracterização dos estudos realizados em Portugal que são ilustrados por tabelas seguidas de discussões; parâmetros na interpretação dos resultados; avaliação crítica e material.

Ribeiro e Almeida (Universidade de Minho), falam sobre as Provas de Avaliação da Realização Cognitiva (P ARC). Trata-se de instrumento constituído por 12 provas que permitem três operações cognitivas (compreensão, raciocínio e pensamento divergente) em função de 4 conteúdos (numérico, figurativo-abstrato, verbal e espacial). Os autores apresentam o teste quanto aos seguintes tópicos: aspectos históricos, fundamentação teórica, população alvo, estudos realizados em Portugal, interpretação dos resultados e avaliação crítica.

O Inventário de Estilos de Pensamento (IEP) é apresentado no Capítulo 8 por Miranda (Universidade de Lisboa). Este instrumento tem como população-alvo adolescentes e adultos e trabalha com o modelo da inteligência como autogoverno mental. São apresentados estudos portugueses e avaliação crítica feita com base nos resultados obtidos nas experiências realizadas.

O Capítulo 9 foi escrito por Machado e Howarth que discutem o Inventário da Aliança Terapêutica (WAI). São apresentados: as indicações, história e fundamentação teórica, caracterização dos estudos realizados em Portugal, parâmetros possíveis de interpretação de resultados em Portugal e avaliação crítica.

Inventário de Sintomas Psicopatológicos (BSI) é o instrumento discutido por Canavarro da Universidade de Coimbra, que segue as indicações, a história, a fundamentação teórica, a caracterização dos estudos realizados em Portugal ilustrados por tabelas seguidas pela respectiva discussão, parâmetros possíveis de interpretação dos resultados e avaliação crítica.

Ferreira e Simões (Universidade de Coimbra) falam sobre as Escalas de Bem-Estar Psicológico - EBEP, que avaliam o bem-estar subjetivo (o instrumento tem sido aplicado em adultos). São apresentados pelos autores: histórico, fundamentação teórica, caracterização dos estudos realizados em Portugal, seguidos de tabelas que discutem os resultados, parâmetros de interpretação dos resultados e avaliação crítica.

No Capítulo 12, é apresentado por Ferreira e Castela o Questionário de Ideação Suicida (QIS), que pretende avaliar a gravidade dos pensamentos suicidas nos adolescentes e jovens adultos. São citadas as indicações quanto a: população alvo, história e fundamentação teórica, caracterização dos estudos realizados em Portugal, parâmetros possíveis de interpretação dos resultados e avaliação crítica.

A Escala de Atitudes Sexuais - EAS - é apresentada por Aferes. Neste capítulo, o autor explica como utilizá-la, avaliá-la e a qual população essa escala se destina. Conta de fundamentação teórica, estudos realizados em Portugal e avaliação crítica.

No capítulo seguinte, Detry e Castro descrevem o Teste de Frustração de S. Rosenzweigh (Forma Adulta). A discussão dos autores está embasada na designação do teste, nas indicações, no enquadramento histórico do teste, na fundamentação teórica, na caracterização dos estudos realizados em Portugal e ao finalizarem fazem uma avaliação crítica do instrumento.

O Capítulo 15 é escrito por Moreira, Almeida e Sampaio, que falam sobre a Escala para 
Avaliação do Comportamento Alimentar (TFEQ), a qual tem por objetivo avaliar três dimensões do comportamento alimentar: restrição cognitiva da ingestão, desinibição e fome. Destina-se à população com idade entre 18 e 30 anos. Os autores discutem o instrumento de maneira clara e objetiva, seguindo a história e a sua fundamentação teórica.

Rodrigues e Ferreira falam sobre as Medidas Intermédias de Avaliação da Aptidão Musical (IMMA). Este instrumento visa auxiliar pais e professores a ministrar a instrução musical adequada ao potencial de cada criança. São apresentadas as indicações do instrumento, a população alvo, a história e a fundamentação teórica, a caracterização dos estudos realizados em Portugal e a avaliação crítica que aponta as vantagens, potencialidades e os limites do instrumento em questão.

Para finalizar o livro, Gonçalves, Morais, Pinto e Machado falam sobre o Teste Aperceptivo de Roberts para Crianças (RA Te), que avalia genericamente a percepção que a criança tem do seu mundo interpessoal. Os autores explicam a constituição do instrumento, a forma de utilizá-lo, a faixa etária indicada, seguida da parte histórica e da fundamentação teórica, dos estudos realizados em Portugal, interpretação dos resultados e avaliação crítica.

Todos os capítulos constam da descrição do material utilizado em cada instrumento, da edição e distribuição e da bibliografia fundamental usada em cada capítulo. É um livro interessante, escrito de um modo claro, apresenta com objetividade os instrumentos. É uma importante ferramenta de trabalho para aqueles profissionais da Psicologia que se interessam pela Avaliação Psicológica. 